\title{
The Gleaner
}

Vol $18(1986)$

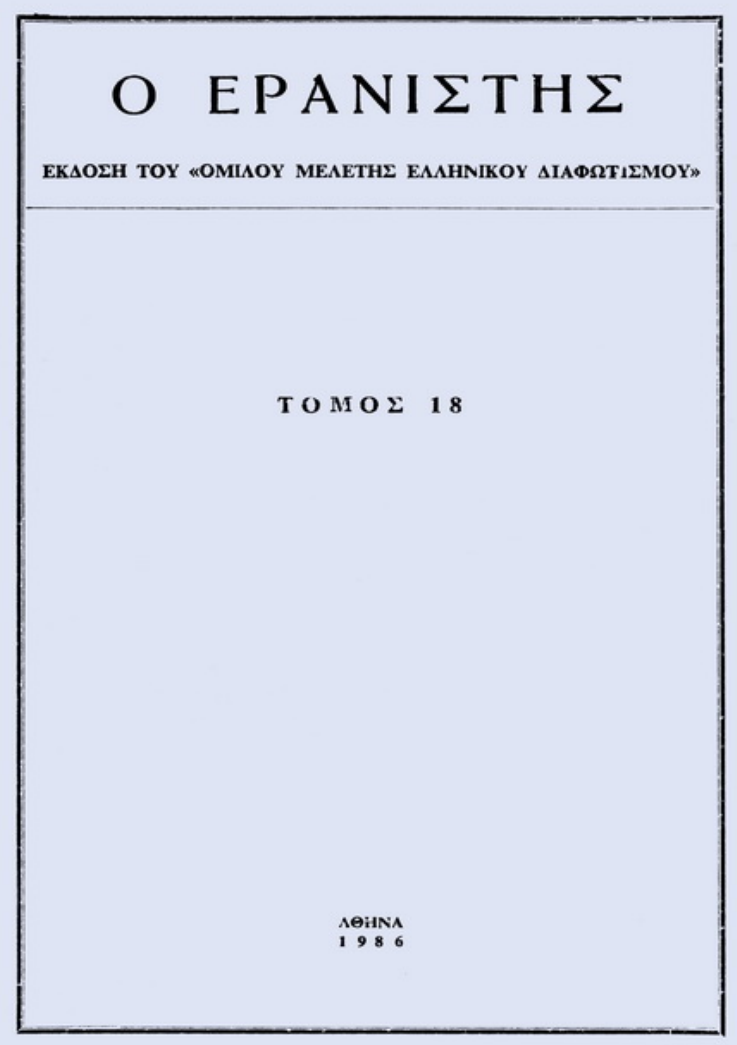

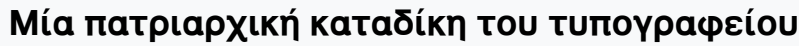

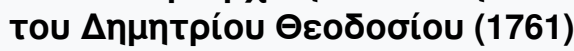

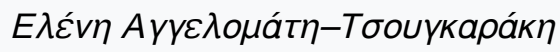

doi: $10.12681 / \mathrm{er} .287$

To cite this article:

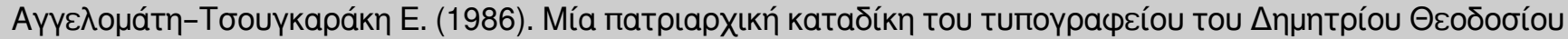
(1761). The Gleaner, 18, 85-92. https://doi.org/10.12681/er.287 


\section{MIA ПАTPIAPXIKH KATA $\triangle$ IKH

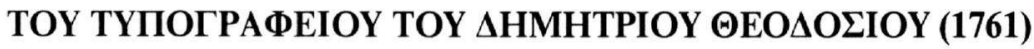

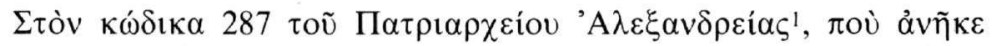

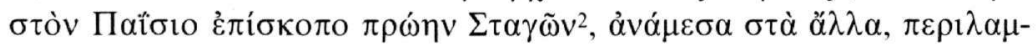

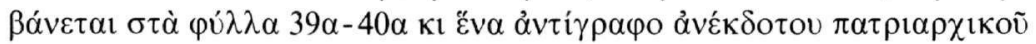

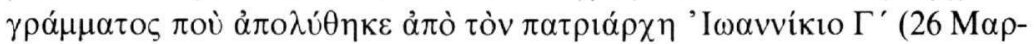

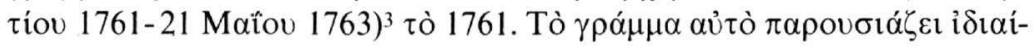

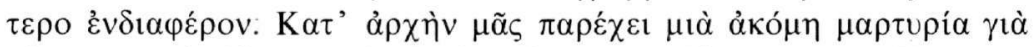

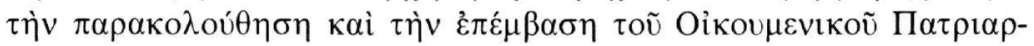

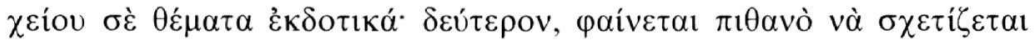

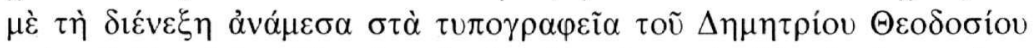

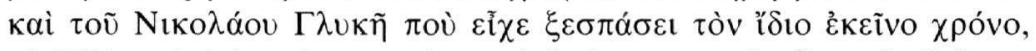

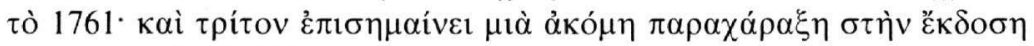
$\lambda \varepsilon \iota \tau о \cup \rho \gamma \iota \kappa \tilde{\omega} v \beta \imath \beta \lambda i \omega v^{4}$.

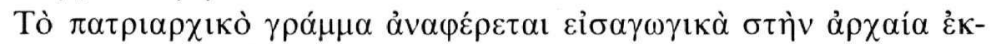

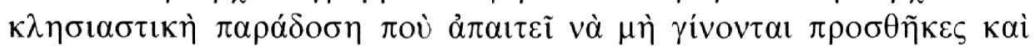

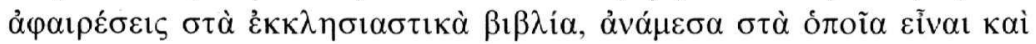

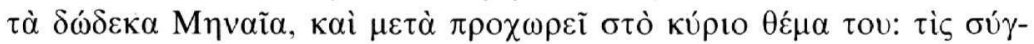

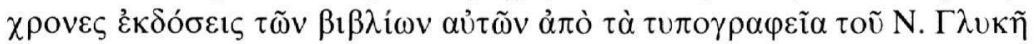

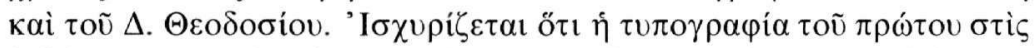

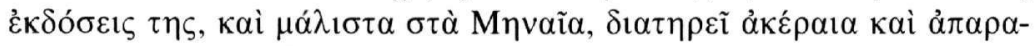

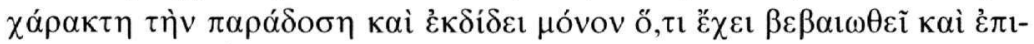

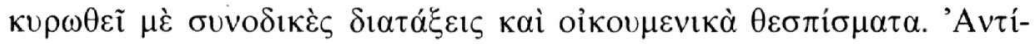

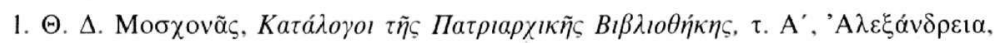

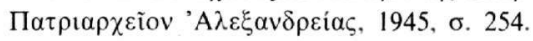

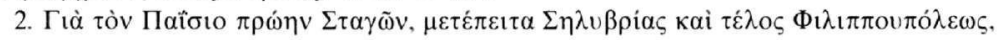

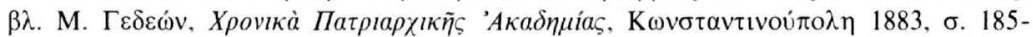

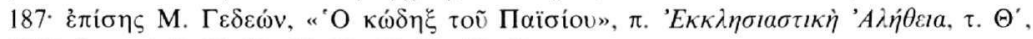
1888-9, б. 4-7, 10-13, 19-22, 29-32, 37-40.

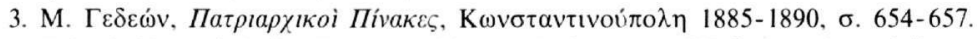

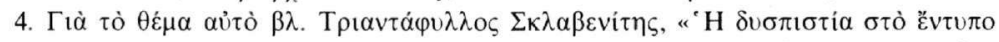

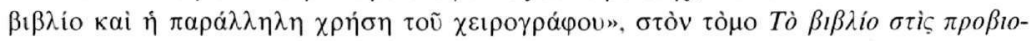

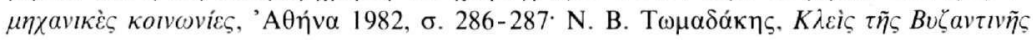

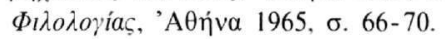




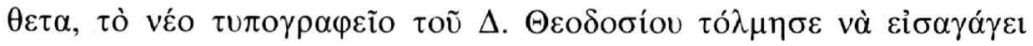

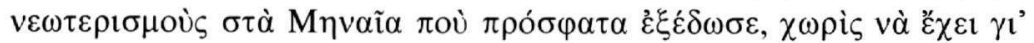

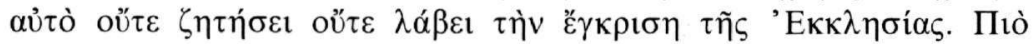

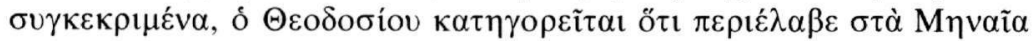

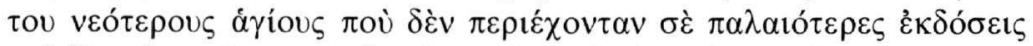

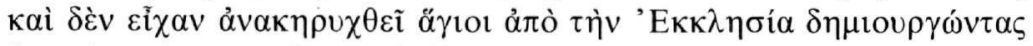

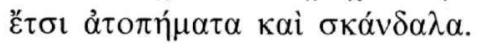

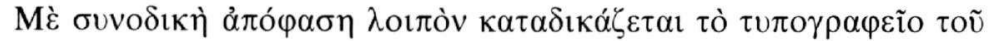

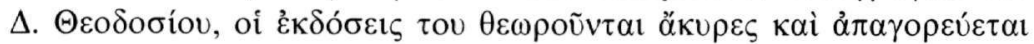

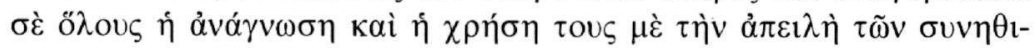

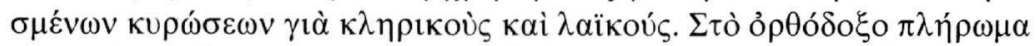

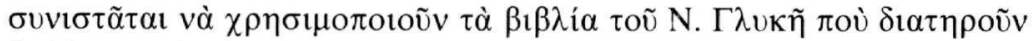

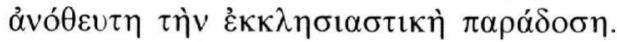

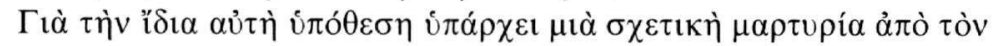

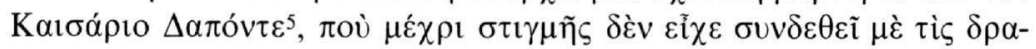

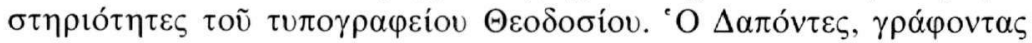

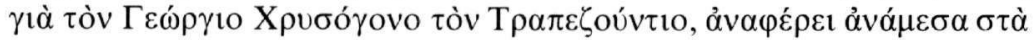

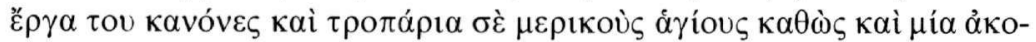

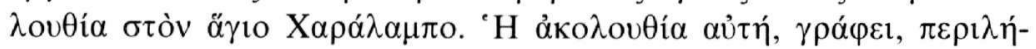

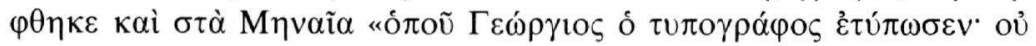

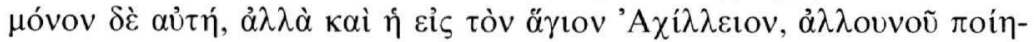

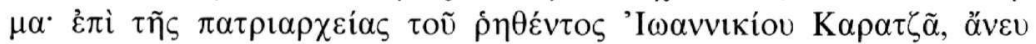

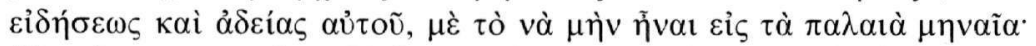

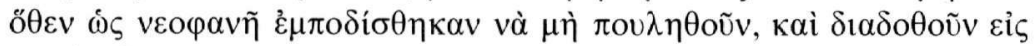

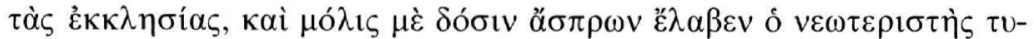

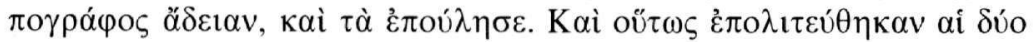

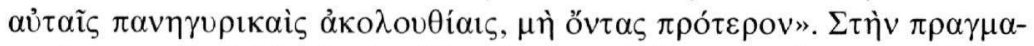

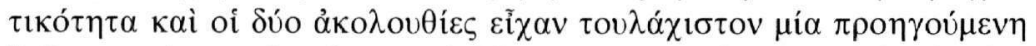

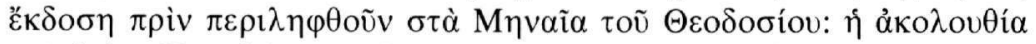

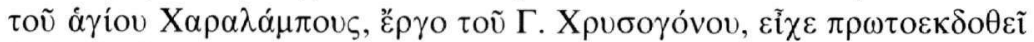

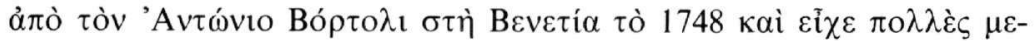

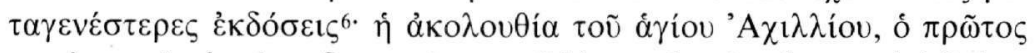

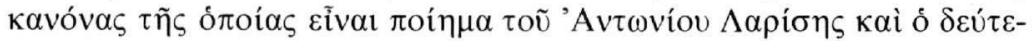

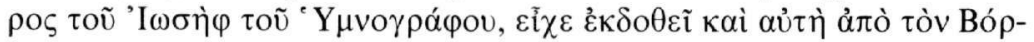

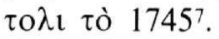

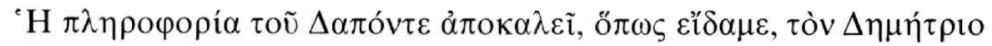

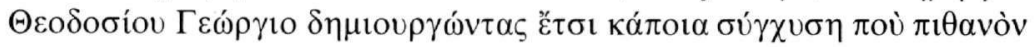

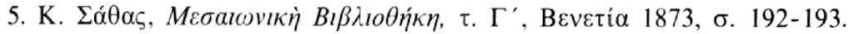

6. Louis Petit, Bibliographie des Acolouthies Grecques, B $\rho v \xi \dot{\varepsilon} \lambda \lambda \varepsilon \varsigma$ 1926, б. 35.

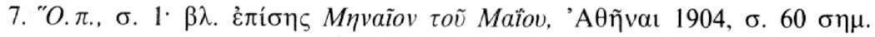




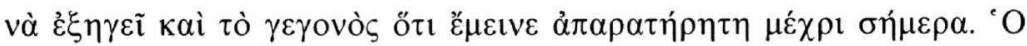

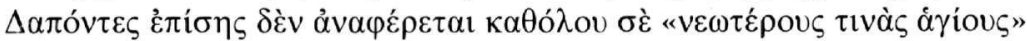

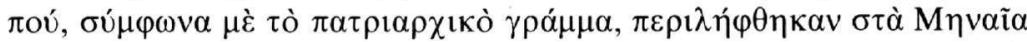

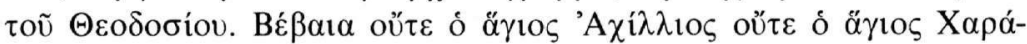

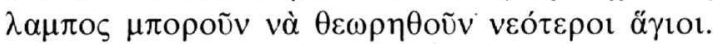

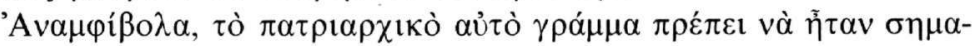

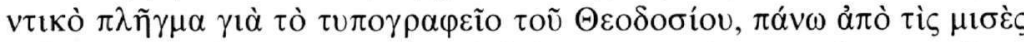

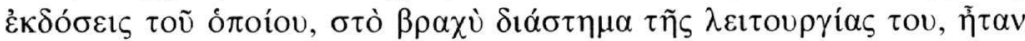

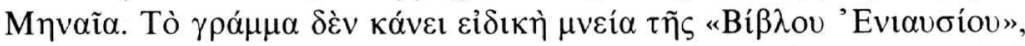

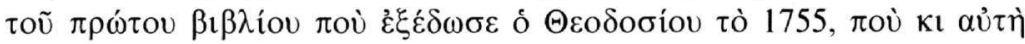

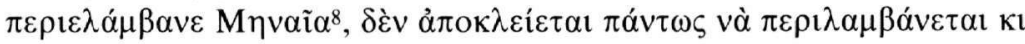

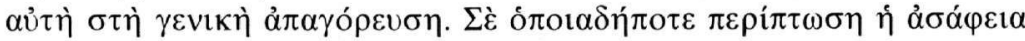

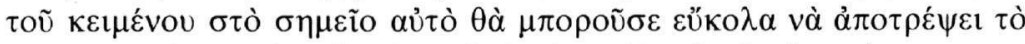

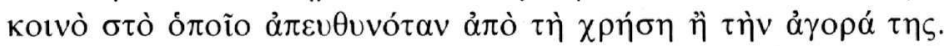

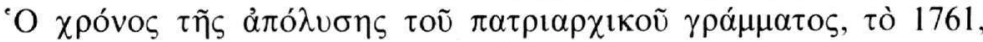

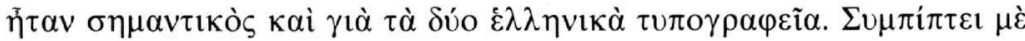

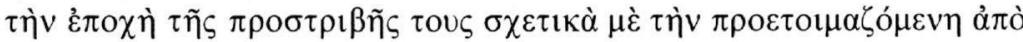

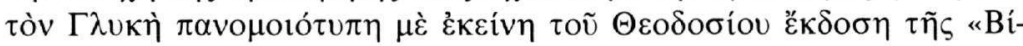

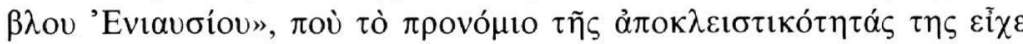

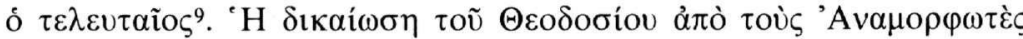

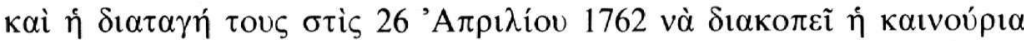

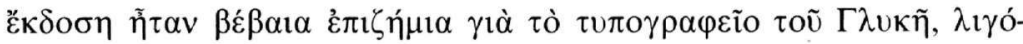

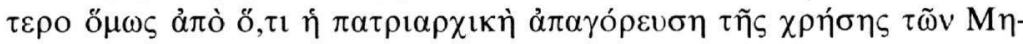

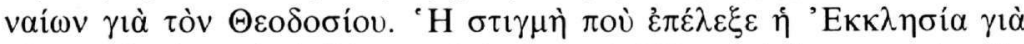

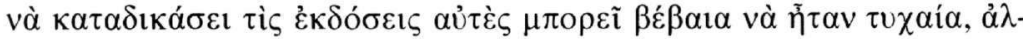

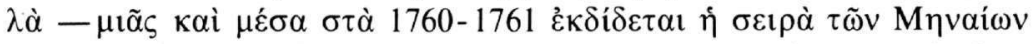

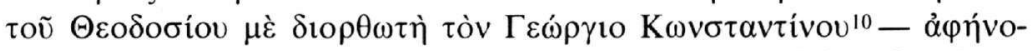

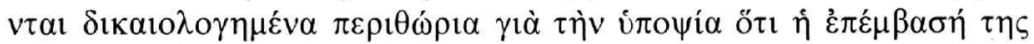

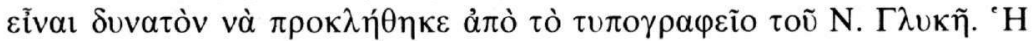

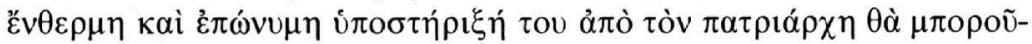

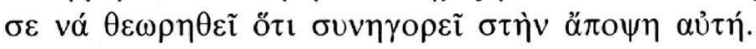

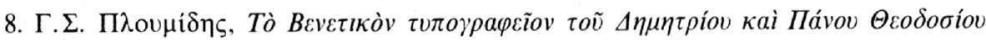

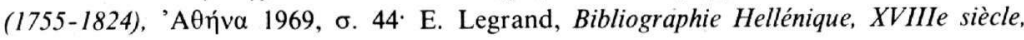

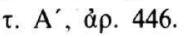

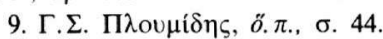

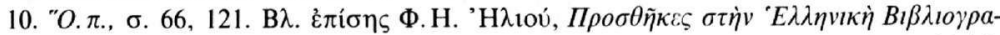

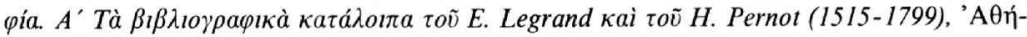
va 1973, б. 173-174, 178-179, 202. 


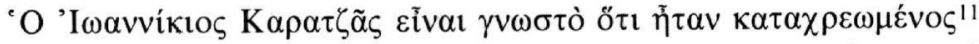

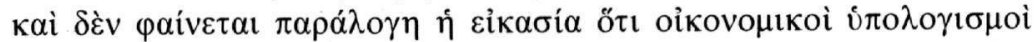

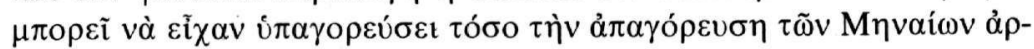
$\chi 1 \kappa \alpha ́$, ő

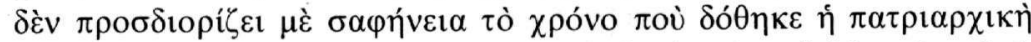

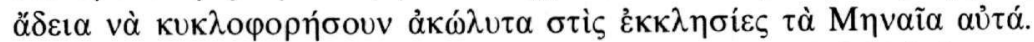

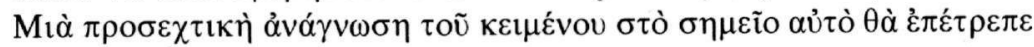

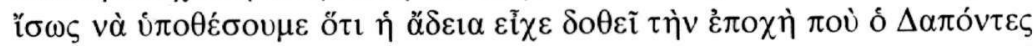

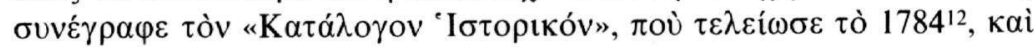

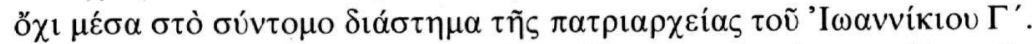

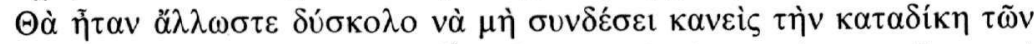

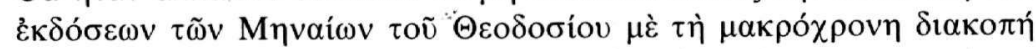

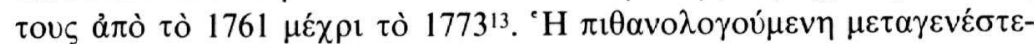

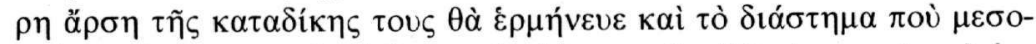

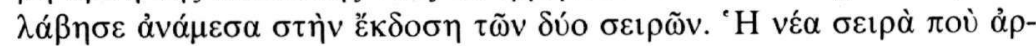

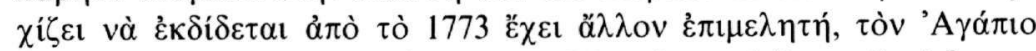

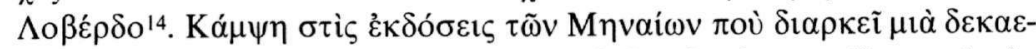

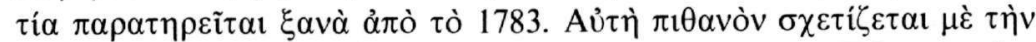

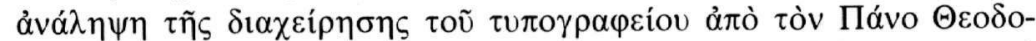

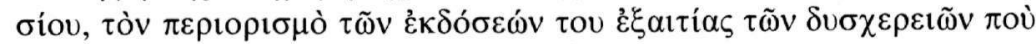

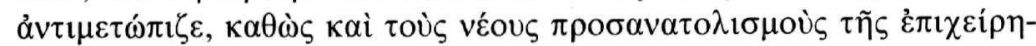

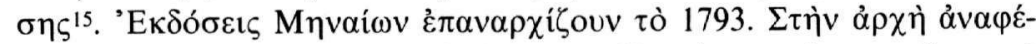

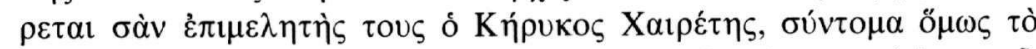

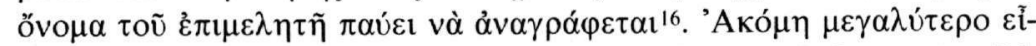

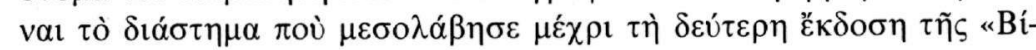

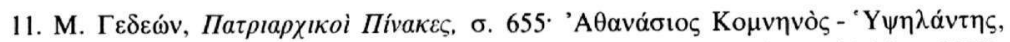

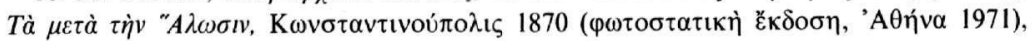
б. 388, 391-393.

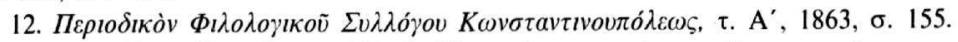

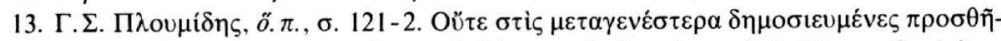

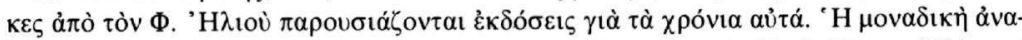

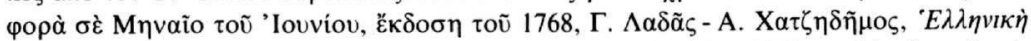

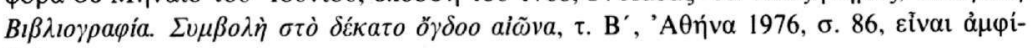
$\beta о \lambda \eta$.

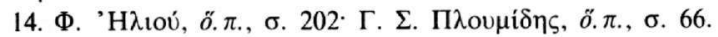

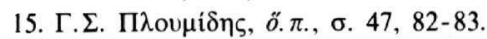

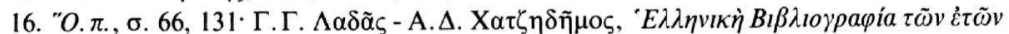

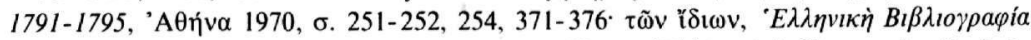

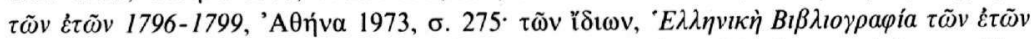

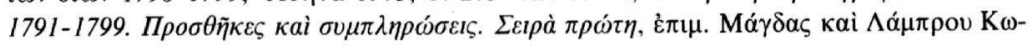

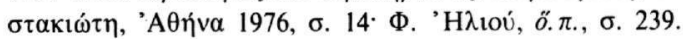




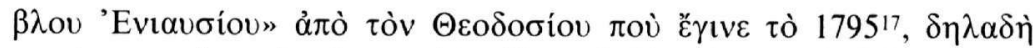

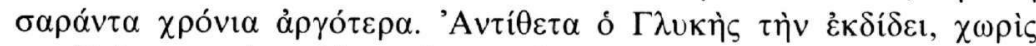

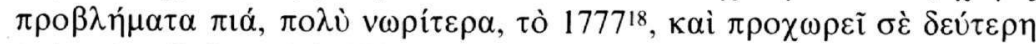

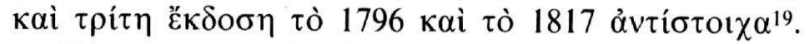

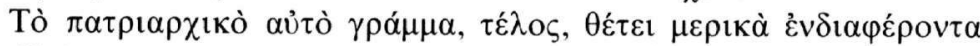

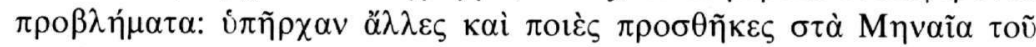

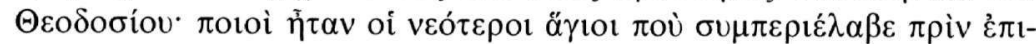

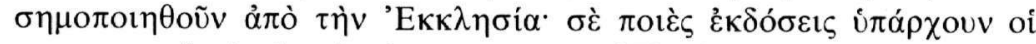

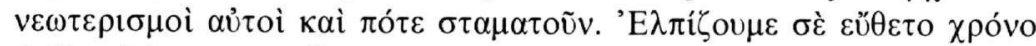

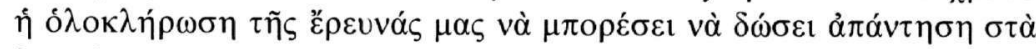

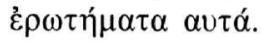

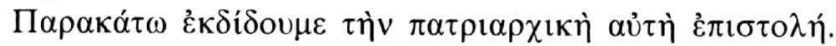

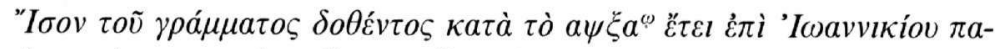

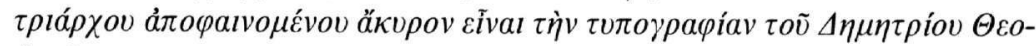
Sooíov.

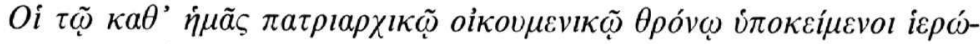

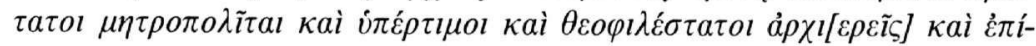

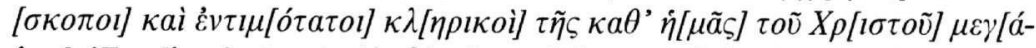

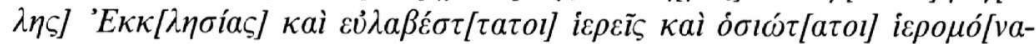

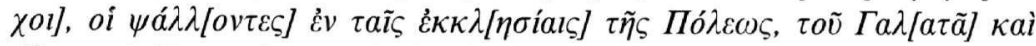

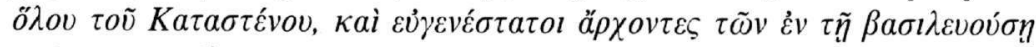

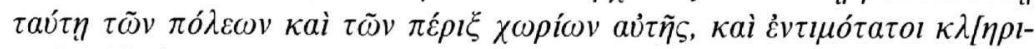

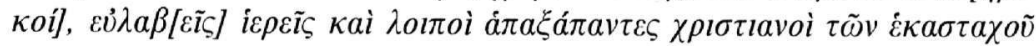

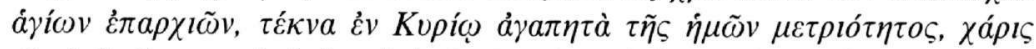

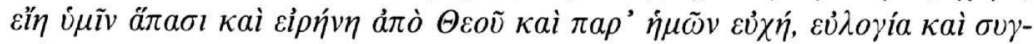
$\chi \omega ́ \rho \eta \sigma \iota \varsigma$.

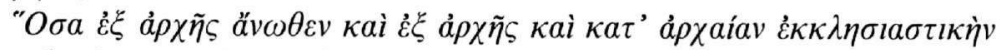

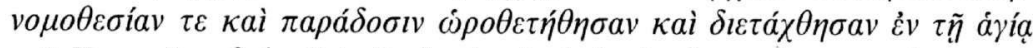

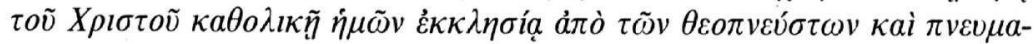

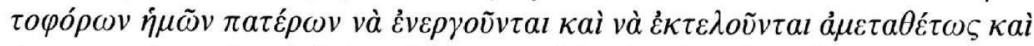

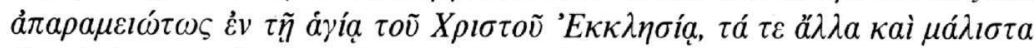

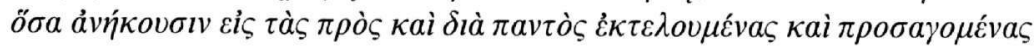

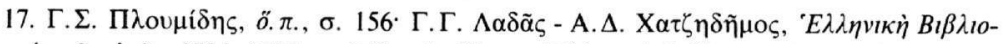

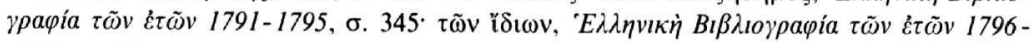
1799 , б. 13.

18. É. Legrand, ö. $\pi .$, å $\rho 75$.

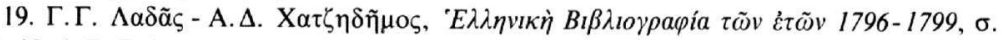

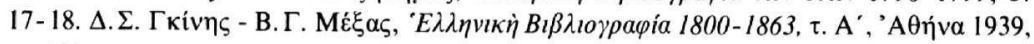
б. 159. 


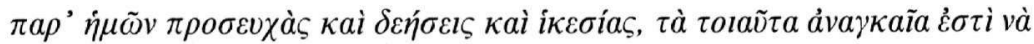

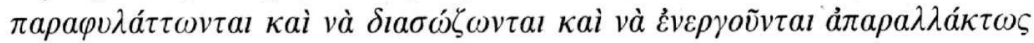

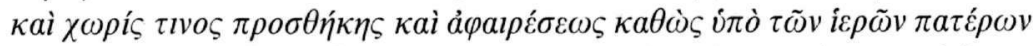

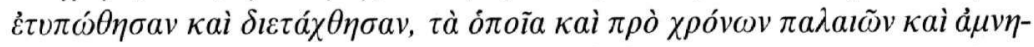

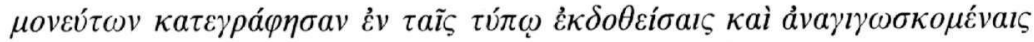

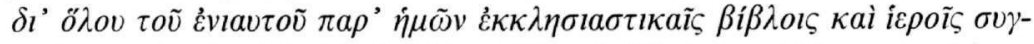

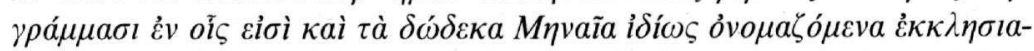

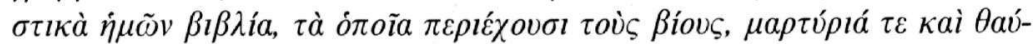

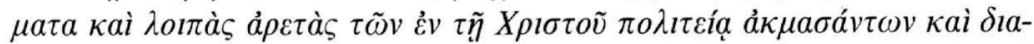

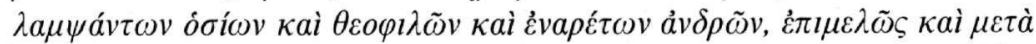

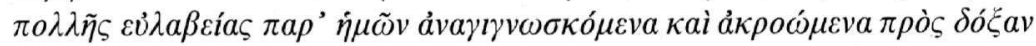

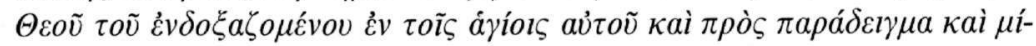

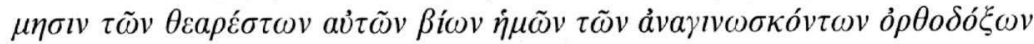

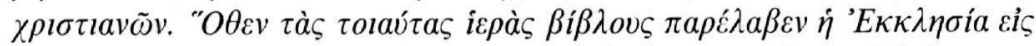

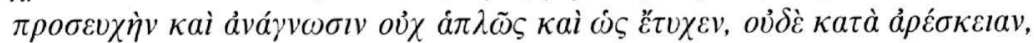

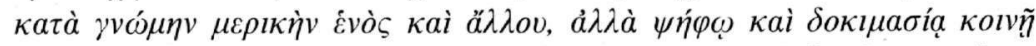

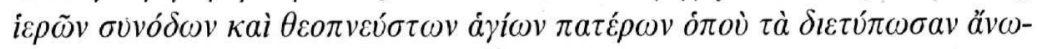

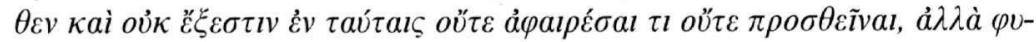

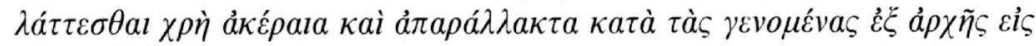

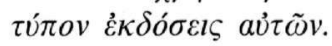

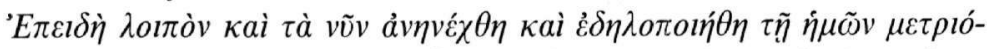

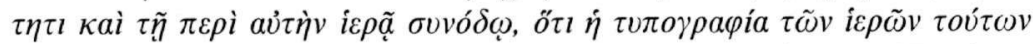

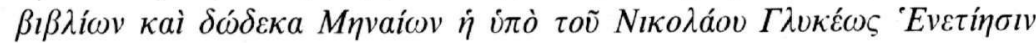

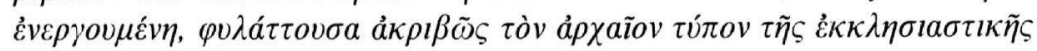

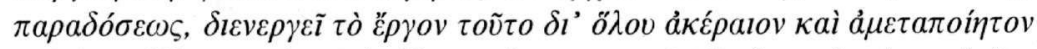

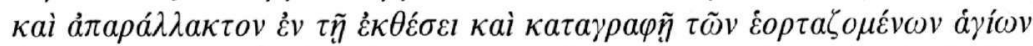

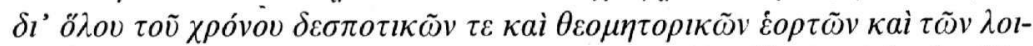

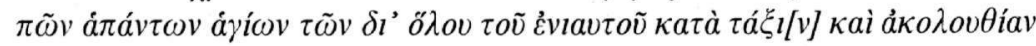

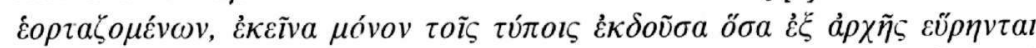

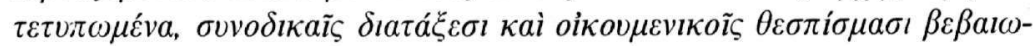

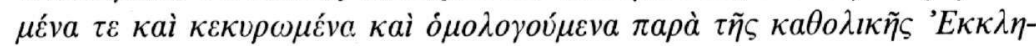

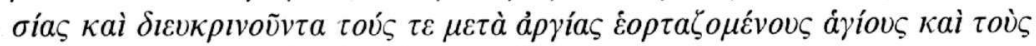

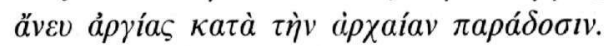

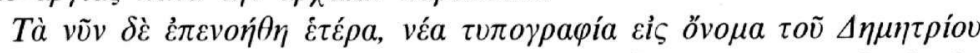

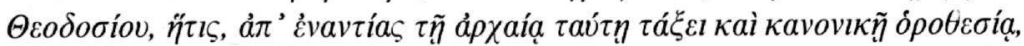

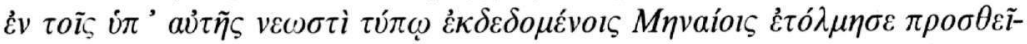

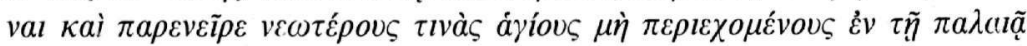

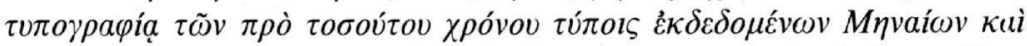

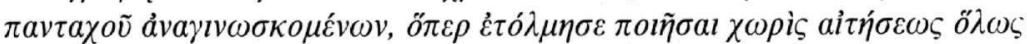

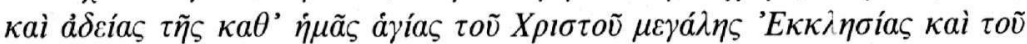

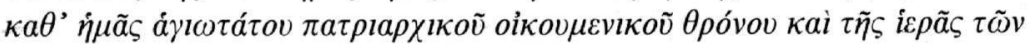




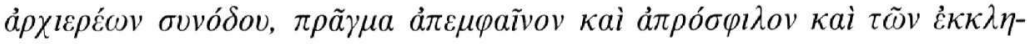

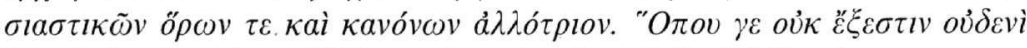

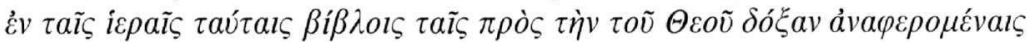

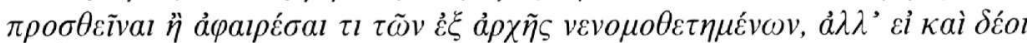

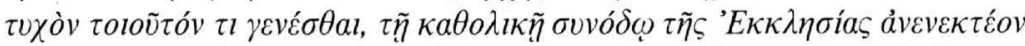

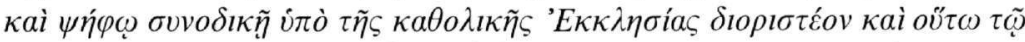

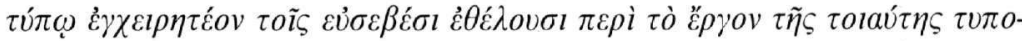

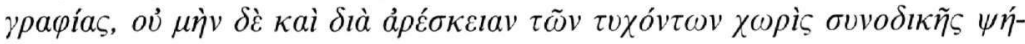

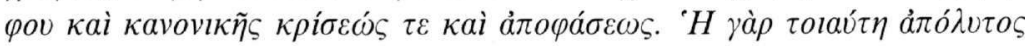

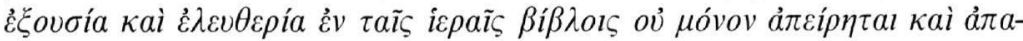

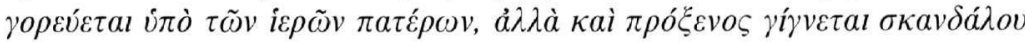

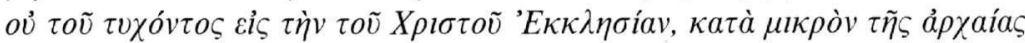

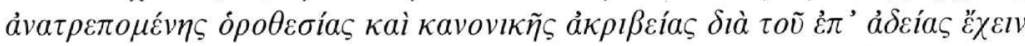

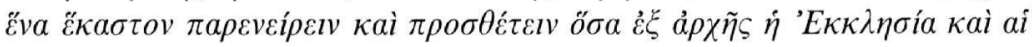

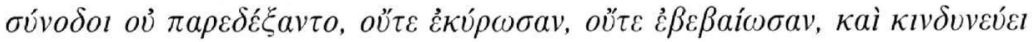

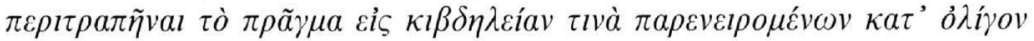

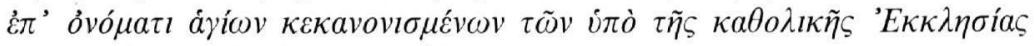

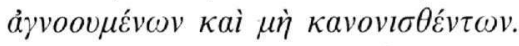

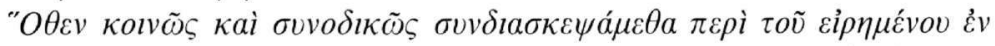

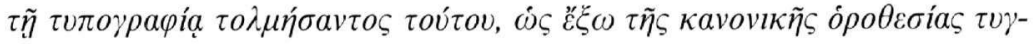

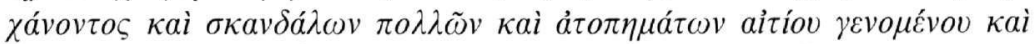

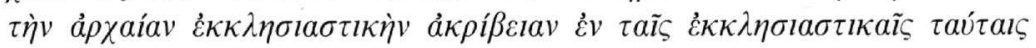

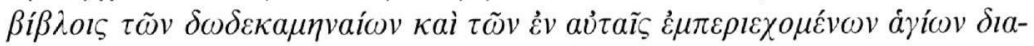

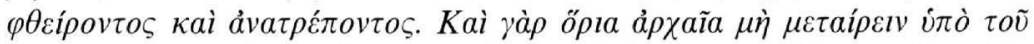

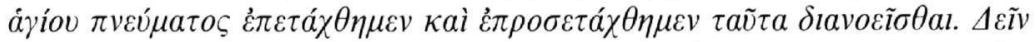

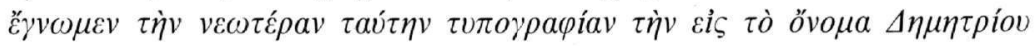

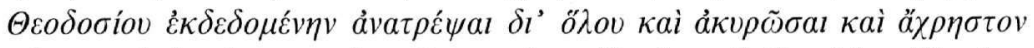

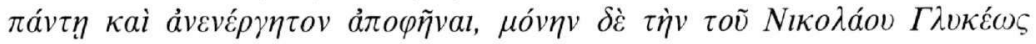

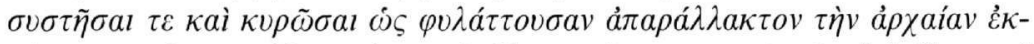

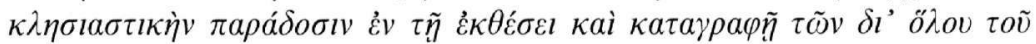

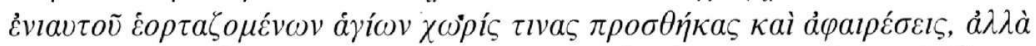

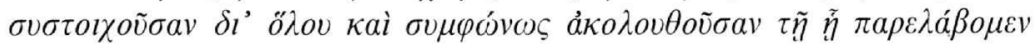

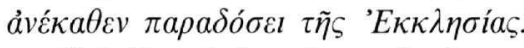

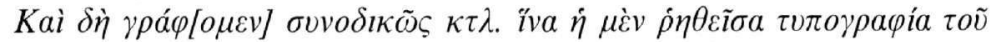

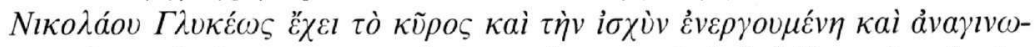

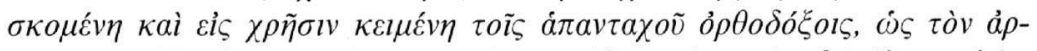

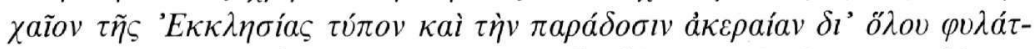

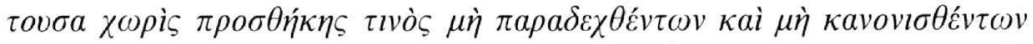

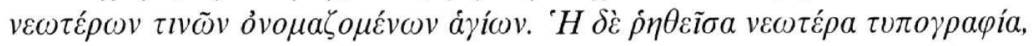

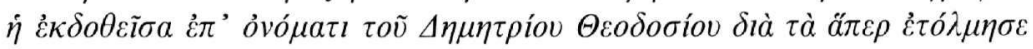

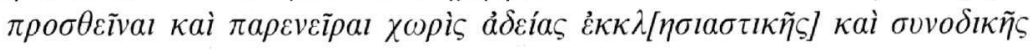




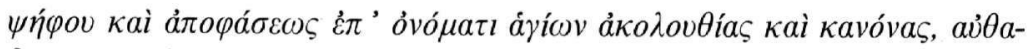

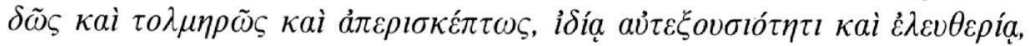

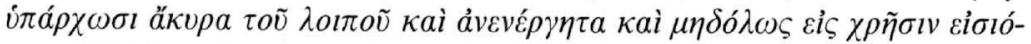

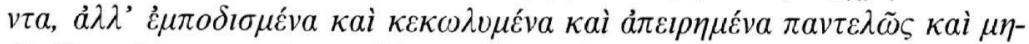

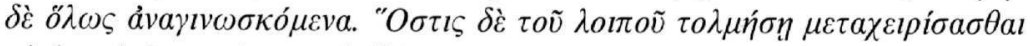

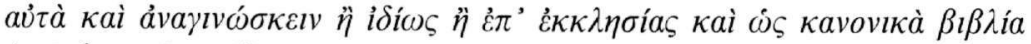

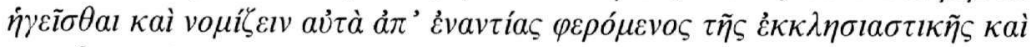

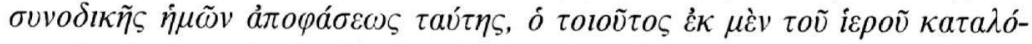

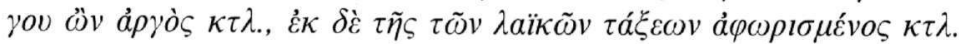

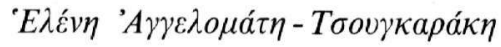

